Elsevier required licence: (C) <2017>. This manuscript version is made available under the CC-BY-NC-ND 4.0 license http://creativecommons.org/licenses/bync-nd/4.0/ 


\title{
Enhancement of nanoscale zero-valent iron immobilization onto electrospun polymeric nanofiber mats for groundwater remediation
}

\author{
Jiawei Ren, Yun Chul Woo, Minwei Yao, Leonard D. Tijing *, Ho Kyong Shon * \\ Centre for Technology in Water and Wastewater, School of Civil and Environmental Engineering, University of \\ Technology Sydney, P. O. Box 123, 15 Broadway, NSW 2007, Australia \\ *Corresponding authors: H.K. Shon, tel: +61 29514 2629, e-mail: Hokyong.shon-1 @ uts.edu.au; L.D. Tijing, tel: \\ +61 29514 2652, e-mail: leonard.tijing@uts.edu.au,
}

\section{Abstract}

A new approach that combines nanoscale zero-valent iron (nZVI) with electrospinning technology has been put forward to avoid nZVI agglomeration and a secondary pollution. In this study, to enhance the immobilization of nZVI particles onto the polyacrylic acid (PAA) / polyvinyl alcohol (PVA) electrospun nanofiber mat, mats (M1,M2 and M3) with different PAA/PVA mass ratios (1:1, 2:1 and 3:1) were tested for the immobilization of nZVI particles and their performance of removing contaminants. The results indicate that M3 immobilized the most nZVI particles (48.4 wt $\%$ on the mat, $\sim 2.5$ times the figure for previous study) and had the highest removals to methylene blue and $\mathrm{Cu}(\mathrm{II})$ ions at $94 \%$ and $83.6 \%$ respectively, resulting from more free carboxylic groups available on the cross-linked nanofibers as well as a higher porosity into the mat. Therefore, increasing the PAA/PVA ratio is effective to boost the performance of nZVI-PAA/PVA electrospun nanofiber mat, which has a great potential for the application of nZVI-targeted contaminants remediation.

Keywords: nZVI particles; Electrospinning; Polymer nanofibers; Immobilization. 


\section{Introduction}

Nanoscale zero-valent iron (nZVI) has been widely used for the reduction of chlorinated organics (Liu et al., 2014; Ma et al., 2012) and heavy metals (Horzum et al., 2013; Xiao et al., 2011) in the groundwater and soil (Tosco et al., 2014). As an in-situ treatment, nZVI particles are generally coated by stabilizers and directly injected into the soil and groundwater (O’Carroll et al., 2013). However, during this process, nZVI particles are prone to agglomerate mutually or adsorbed onto soil grains, thereby reducing the reaction sites with the contaminants in the groundwater (Dror et al., 2012). Meanwhile, these nZVI particles are too mobile to be distributed uniformly for wide exposure to the contaminated groundwater and also can cause a secondary pollution downstream. Thus, it is necessary to develop a new method to optimize and immobilize nZVI particles.

An electrospun polymer nanofiber mat is an excellent carrier to immobilize nZVI due to its low cost, large specific surface area, high porosity and its immobility in liquid phases (Wan et al., 2007; Xiao et al., 2009). Large specific area of the nanofiber mat enables the nZVI particles to be more dispersive and a smaller size, which can increase more reaction sites to reduce contaminants. Similarly, high porosity makes it possible for nZVI particles to contact raw water effectively and ensure a relatively stable water flux. The immobility of the mat can also hinder the agglomeration of nZVI particles. Meanwhile, the immobilized nZVI particles can easily be recycled from the mat and essentially avoid undesirable secondary pollution. Liu et al. (Liu et al., 2014) immobilized nZVI in the polyacrylonitrile (PAN)-based oxidized mat to reduce water contaminants (including methylene blue and trichloroethylene), which had shown an excellent performance on the removal of each contaminant. It is also reported that chitosan fiber-supported nZVI particles was an excellent sorbent material for inorganic arsenic uptake at concentration ranging from 0.01 to $5.00 \mathrm{mg} / \mathrm{L}$ (Horzum et al., 2013). Compared with individual nZVI particle, the nZVI-immobilized mat can not only be used as an in-situ 
treatment method, like a classical permeable reactive barrier (PRB) process (Wilkin et al., 2014), but also be used as a pump \& treat technology, like a typical filtration process (Ma et al., 2015). Thus, there are more forms and opportunities for the applications of the nZVIimmobilized mat in groundwater remediation.

The material requirement for the mat fabrication varies with functions. Traditional electrospun materials are usually polymers, such as polyvinyl alcohol (PVA), nylon-6, PAN (Woo et al., 2015) and polyvinylidene fluoride (PVDF) and its copolymers (Woo et al., 2016), which exhibit high mechanical strength, stretching capability and chemical resistance. However, in terms of immobilizing nZVI particles, these polymers lack specific functional groups (like carboxylic group, -COOH) to bond with nZVI particles. Polyacrylic acid (PAA) is widely used as a coating of nZVI for groundwater remediation due to its high ratio of COOH group and its nontoxicity in water (Lin et al., 2010; Schrick et al., 2004). However, it is difficult for PAA itself to be fabricated into nanofibers via electrospinning due to its low solution viscosity (Li and Hsieh, 2005b). Additionally, neat PAA fibers are not stable in water ambiance because of its high solubility. Thus, PVA, whose monomer has hydroxide group ($\mathrm{OH})$, is usually blended with PAA to increase the solution viscosity to produce nanofibers and after electrospinning, is cross-linked with PAA to make it water-insoluble. Xiao et al. (Kocur et al., 2013) first used the electrospun PAA/PVA nanofibers to immobilize nZVI and the fiberssupported nZVI showed superior capability to decolorize acid fuchsine solution. Also, Ma et al. (Ma et al., 2012) reported the use of electrospun PAA/PVA nanofiber mats to immobilize $\mathrm{Fe} / \mathrm{Pd}$ bimetallic nanoparticles, which significantly improved the degradation efficiency of trichloroethylene. However, all of the previous reports prepared the PAA/PVA solution at 1:1 mass ratio, whose mole ratio of their monomers was only at $0.61: 1$. This indicated that the $\mathrm{COOH}$ groups in the mat were much less than the $-\mathrm{OH}$ groups and mostly consumed during 
esterification. Therefore, for getting more of free $-\mathrm{COOH}$ groups to bond with nZVI particles, increasing the PAA/PVA ratio is considered to be a theoretically feasible way.

In this study, we report a promising approach in improving the immobilization of nZVI particles onto PAA/PVA electrospun fibrous mats by increasing PAA/PVA ratio. First, different concentrations and ratios of PAA/PVA solutions were used to fabricate nanofiber membranes via an electrospinning technology. Thermal crosslinking was then introduced to make the nanofiber mats water-insoluble. The water-insoluble mats were bonded with the Fe(II) ions, which were directly reduced and formed into nZVI particles on the mats. The decolorization efficiency of the nZVI-immobilized mats was examined using methylene blue as a model dye contaminant and the removal of $\mathrm{Cu}(\mathrm{II})$, as a model heavy metal, was examined as well. The nZVI-immobolized mats displayed an excellent reactivity toward the decolorization of the model dye solution and the removal of the model heavy metal solution. To our best knowledge, this is the first attempt related to effects of PAA/PVA ratio on the immobilization of nZVI onto electrospun polymer nanofiber mats.

\section{Materials \& Methods}

\subsection{Materials}

Polyacrylic acid (PAA, Mv = 450,000), polyvinyl alcohol (PVA, 87-89\% hydrolysed, $\mathrm{Mw}=85,000-124,000)$, ferrous (II) sulphate heptahydrate $\left(\mathrm{FeSO}_{4} \cdot 7 \mathrm{H}_{2} \mathrm{O}\right)$, sodium borohydride $\left(\mathrm{NaBH}_{4}\right)$, cupric(II) nitrate $\left(\mathrm{Cu}\left(\mathrm{NO}_{3}\right)_{2}\right)$, methylene blue and ethanol were all purchased from Sigma-Aldrich. Deionized (DI) water from a Millipore Milli-Q water system was used; all the oxygen-free water was prepared by purging nitrogen gas for 10 mins to remove the dissolved oxygen and avoid the oxidation of the nZVI. 


\subsection{Solution preparation}

In this study, a large number of electrospinning experiments were conducted to find out well-electrospun PAA/PVA nanofiber mats. Concentration of PVA was varied from $5 \mathrm{wt} \%$ to $25 \mathrm{wt} \%$ while the neat PAA solution was prepared from $7.5 \mathrm{wt} \%$ to $54 \mathrm{wt} \%$ to make the mass ratio of PAA in the mixed solution no less than that of PVA.

All the PVA solutions were prepared by dissolving PVA into DI water stirring at $90^{\circ} \mathrm{C}$ until completely dissolved, and then cooled down to room temperature. Meanwhile, PAA solutions were prepared by dissolving PAA into a mixed solvent composed of DI water and ethanol (3:1 by wt\%) at room temperature with magnetic stirring overnight.

To prepare the blend solution (PAA/PVA), each PAA solution was poured over the PVA solution and continued stirring for $24 \mathrm{~h}$ to ensure proper mixing. The blended mass of each PAA solution was identical with that of each PVA solution.

\subsection{Electrospinning and cross-linking of PAA/PVA nanofiber mats}

The electrospinning set-up is shown in Fig.1. Nanofibers were directly fabricated onto a rotating drum collector covered with baking paper in a sealed chamber (Woo et al., 2015). All the fabricated mats were electrospun at an employed voltage of $10-20 \mathrm{kV}$. The tip-to-collector distance (TCD) was $15 \mathrm{~cm}$ and the feed flow rate was controlled at $0.5 \mathrm{ml} / \mathrm{hr}$ by a syringe pump. 


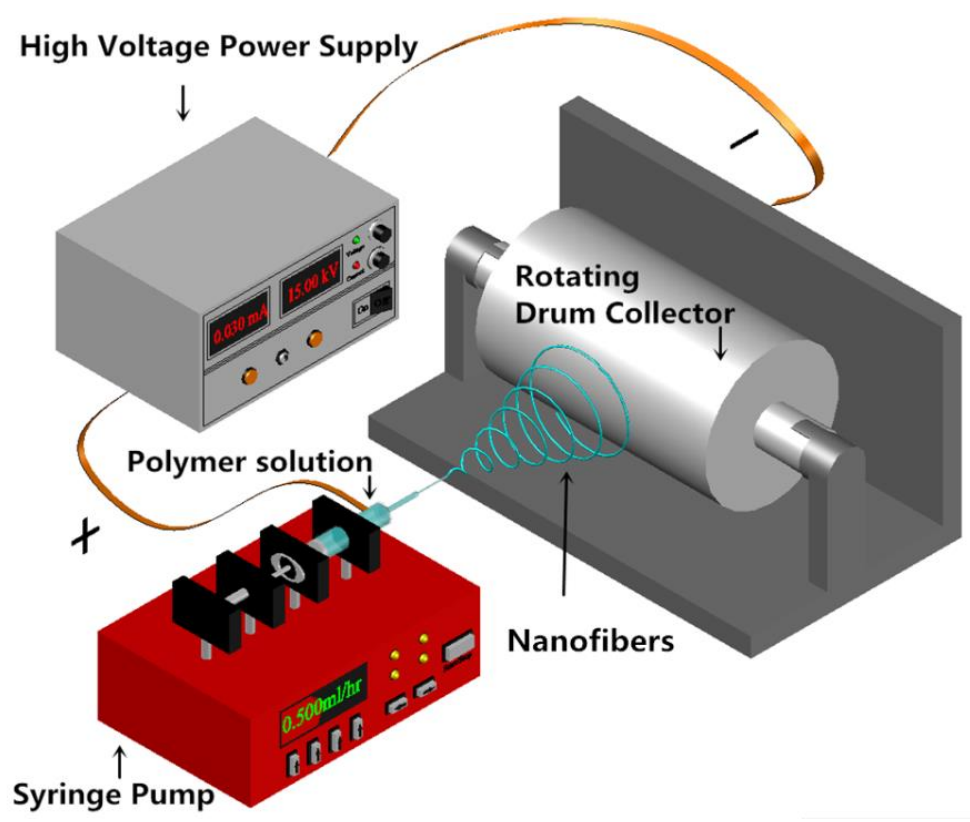

Figure 1. Schematic diagram of the electrospinning configuration

The polymer solution was supplied by a $12 \mathrm{ml}$ syringe attached with a needle $(21 \mathrm{G}$, inner diameter $=0.51 \mathrm{~mm}$ ) connected via a metallic adaptor. The relative humidity in the sealed chamber was maintained at 50 60\% during the electrospinning process. All the mats were fabricated for $8 \mathrm{hrs}$. After electrospinning, the as-spun mats were removed from the collector and put into a dry oven directly without any cover (to avoid mat shrinkage) at $60^{\circ} \mathrm{C}$ for 1 day to remove the residual solvent (Woo et al., 2015). Then, the dried mats were cross-linked by thermal treatment in an oven at $145^{\circ} \mathrm{C}$ for 30 min to make them water-stable (Xiao et al., 2010). To check the stability of the cross-linked mats in water, All the mats were submerged into DI water for $24 \mathrm{hrs}$, and the water stability is described by the gelation content of mats, calculated via the following equation (Chun et al., 2005):

$$
\text { Gelation Content(\%) }=\frac{\mathrm{w}_{1}}{\mathrm{w}_{0}} \times 100 \%
$$

where $\mathrm{w}_{0}$ is the weight of mat before soaking in water, while $\mathrm{w}_{1}$ is the weight of the mat after soaking in water and dried for $24 \mathrm{hrs}$ in an oven. 


\subsection{Synthesis and immobilization of nanoscale zero valent iron (nZVI)}

After crosslinking treatment, mats with different PAA/PVA ratios were soaked into 0.2 $\mathrm{mol} / \mathrm{L} \mathrm{FeSO}_{4}$ solution for $3 \mathrm{hrs}$ to allow the complexation of ferrous ions and the rest of free $\mathrm{COOH}$ groups from PAA. Then the mats were rinsed by oxygen-free DI water for the removal of the residual ferrous solution. After that, $\mathrm{NaBH}_{4}$ solution $(0.4 \mathrm{~mol} / \mathrm{L})$ was added to the mats drop by drop onto/into the mats in an anaerobic chamber (filled by $\mathrm{N}_{2}$ gas) to form and immobilize nZVI particles. The reaction is shown below (Wang et al., 2008),

$$
\mathrm{Fe}^{2+}+2 \mathrm{BH}_{4}^{-}+6 \mathrm{H}_{2} \mathrm{O} \rightarrow \mathrm{Fe}^{0} \downarrow+2 \mathrm{~B}(\mathrm{OH})_{3}+7 \mathrm{H}_{2} \uparrow
$$

The successful formation of nZVI on the electrospun mat is indicated by the change of color of the mat into black, and once the black color was stable, the nZVI-PAA/PVA mats were rinsed and stored in ethanol in a sealed glass bottle, which was filled with nitrogen gas.

\subsection{Characterization and measurements}

2.5.1 Scanning electron microscopy (SEM) and energy-dispersive X-ray spectroscopy (EDS)

The surface and cross-sectional morphologies of all the mats were observed by scanning electron microscopy and energy dispersive X-ray spectrometry (SEM and EDS, Zeiss Supra 55VP, Carl Zeiss AG). Samples taken from each mat were coated by Au/Pd prior to SEM. The SEM images were carried out at an accelerating voltage of $10 \mathrm{kV}$, and multiple image magnifications at various areas were obtained for each sample (Woo et al., 2015).

2.5.2 Attenuated total reflectance - Fourier transform infrared spectroscope (ATR- FTIR)

Each sample was analyzed by attenuated total reflectance Fourier transform infrared spectroscopy (ATR-FTIR) via Paragon 1000 Spectrometer (PerkinElmer, USA) in the range of $600-4000 \mathrm{~cm}^{-1}$ with a signal resolution of $1 \mathrm{~cm}^{-1}$ and a minimum of 32 scans. 


\subsubsection{Porosity}

The mat porosity, defined as the volume of pores divided by the total volume of the mat, was measured via a gravimetric method (Woo et al., 2015). Mat samples with equal sizes (2 $\mathrm{cm} \times 2 \mathrm{~cm}$ ) were wetted by ethanol for $24 \mathrm{hrs}$ to ensure the pores were fully filled up. The weight of the samples was measured before and after soaking in the ethanol. The mat porosity was determined by the following equation (Yao et al., 2016):

$$
\rho=\frac{\left(\mathrm{W}_{1}-\mathrm{W}_{2}\right) / \mathrm{D}_{\mathrm{e}}}{\left[\left(\mathrm{W}_{1}-\mathrm{W}_{2}\right) / \mathrm{D}_{\mathrm{e}}\right]+\mathrm{W}_{2} / \mathrm{D}_{\mathrm{p}}}
$$

where $\rho$ is the porosity, $\mathrm{W}_{1}$ is the weight $(\mathrm{g})$ of the ethanol-saturated mat, $\mathrm{W}_{2}$ is the weight $(\mathrm{g})$ of the dry mat, $D_{e}$ is the density $\left(\mathrm{g} / \mathrm{m}^{3}\right)$ of ethanol and $\mathrm{D}_{\mathrm{p}}$ is the overall density $\left(\mathrm{g} / \mathrm{m}^{3}\right)$ of PVA and PAA material.

\subsubsection{Thermo-gravimetric analysis}

Thermo-gravimetric analysis (TGA) was carried out on Discovery TGA thermogravimetric analyzer (SDT-Q600, United States) from $50^{\circ} \mathrm{C}$ to $700^{\circ} \mathrm{C}$ at a heating rate of $10^{\circ} \mathrm{C} / \mathrm{min}$ in $\mathrm{N}_{2}$ atmosphere. The crucible material was platinum (PN: 960149.901, United States). Each sample was dried by purging $\mathrm{N}_{2}$ for 1 min before measurement.

\subsection{Performance of nZVI-PAA/PVA nanofiber mat}

\subsubsection{Decolorization of Methylene Blue}

Methylene blue is a commonly-used chloride dye, selected in this study to test the performance of nZVI-PAA/PVA nanofiber mats. In order to specify the effects of the adsorption of PAA/PVA mats and the reduction of nZVI particles, mats with different PAA/PVA ratios were compared both with and without nZVI. Each mat was soaked in $25 \mathrm{~mL}$ of $25 \mathrm{mg} / \mathrm{L}$ methylene blue solution and the bare weight of each mat (before soaking in the $\mathrm{FeSO}_{4}$ solution) in the dye solution was kept at $8 \mathrm{mg}$. After shaking at $100 \mathrm{rad} / \mathrm{min}$ for $6 \mathrm{hrs}$ 
on a platform mixer, $5 \mathrm{~mL}$ supernatant liquid sample was withdrawn for the analysis of decolorization efficiency by an ultraviolet visible spectrophotometer (UV-1700, Shimadzu, Japan) in the wavelength range of 400 to $800 \mathrm{~nm}$. The decolorization efficiency was calculated using the following equation:

$$
\text { Decolorization efficiency }(\%)=\frac{\mathrm{C}_{\text {int }}-\mathrm{C}_{\text {end }}}{\mathrm{C}_{\mathrm{int}}} \times 100 \%
$$

where, $\mathrm{C}_{\mathrm{int}}$ and $\mathrm{C}_{\mathrm{end}}$ are the initial and the final methylene blue concentrations, respectively.

\subsubsection{Removal of $\mathrm{Cu}(\mathrm{II})$ ions}

To further evaluate the heavy metal removal capability of nZVI-PAA/PVA mats, $\mathrm{Cu}\left(\mathrm{NO}_{3}\right)_{2}$ solution was also selected in this study to test the performance of nZVI-PAA/PVA nanofiber mats. In the similar method as methylene blue, each mat $(8 \mathrm{mg})$ was soaked in $25 \mathrm{ml}$ $\mathrm{Cu}\left(\mathrm{NO}_{3}\right)_{2}$ solution $(25 \mathrm{mg} / \mathrm{L})$. The solution was then subjected to shaking using a platform mixer at $100 \mathrm{rad} / \mathrm{min}$ for $6 \mathrm{hrs}$. Supernatant liquid samples $(5 \mathrm{ml})$ were withdrawn for the analysis of $\mathrm{Cu}(\mathrm{II})$ concentration via microwave plasma-atomic emission spectrometry (4100 MP-AES, Agilent Technologies, United States). The Cu(II) removal was determined using the following equation:

$$
\mathrm{Cu}(\mathrm{II}) \text { removal efficiency }(\%)=\frac{\mathrm{C}_{\text {int }}-\mathrm{C}_{\text {end }}}{\mathrm{C}_{\text {int }}} \times 100 \%
$$

where, $\mathrm{C}_{\mathrm{int}}$ and $\mathrm{C}_{\text {end }}$ refer to the initial and final $\mathrm{Cu}(\mathrm{II})$ concentrations, respectively.

\section{Results and discussion}

\subsection{Effect of PAA/PVA ratio on the electrospinning of nanofibers}

The properties of polymer solution and the process parameters of electrospinning greatly affect the resulting morphology and structure of the electrospun nanofiber mats. $\mathrm{T}$ determine 
the optimum polymer solution concentrations and produce well-electrospun nanofibers, preliminary electrospinning experiments were conducted over three stages (see Table S1). Based from these experiments, the concentration of PVA played the most significant role in the formation of nanofibers for the blend solution and the $18 \mathrm{wt} \%$ PVA showed the best performance after its stable fibrous structure with the lowest PVA percentage. Thus, in this study, the concentration of PVA was fixed at $18 \mathrm{wt} \%$, while the neat PAA solution was varied from 18, 36 and $54 \mathrm{wt} \%$ (equivalent to PAA/PVA mass ratio of 1:1, 2:1, and 3:1 respectively), making sure that the mass of PAA in the mixed solution was no less than that of PVA.

Fig. 2 shows the SEM images of as-spun PAA/PVA nanofiber mats at different blend ratios. All nanofiber mats showed ultrafine structure, with cylindrical and beadless mats showing defect-free membranes. The average fiber sizes of the three mats with 1:1, 2:1 and 3:1 PAA/PVA ratios (referred hereinafter as M1, M2 and M3 mats respectively) were $415 \pm 57$, $511 \pm 55$ and $735 \pm 87 \mathrm{~nm}$, respectively. The fiber size increased with the increase of PAA/PVA ratio, which could be attributed to the corresponding increase of total polymer concentration, leading to higher viscosity and lower surface tension. Higher viscosity can hinder the stretching of jet, thereby weakening the whipping effect and increasing the fiber size, as also observed by previous studies ( $\mathrm{Li}$ and Hsieh, 2005a). Additionally, a higher PAA/PVA mass ratio had a more dispersive size distribution, which may contribute to a higher porosity and permeability of the mat. 


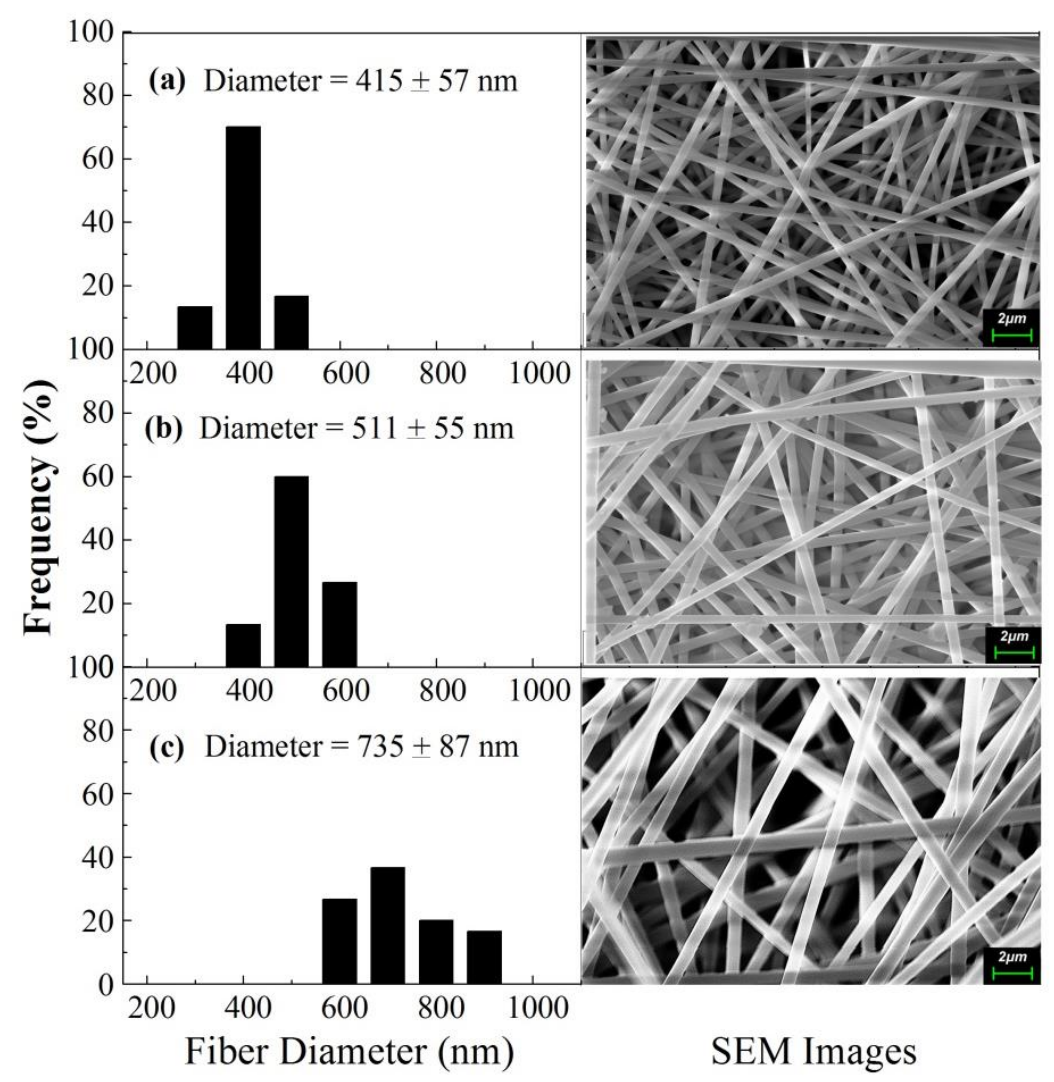

Figure 2. Effect of PAA/PVA ratio on the fiber sizes of the as-spun mats

(a) M1, PAA/PVA = 1:1; (b) M2, PAA/PVA = 2:1; (c) M3, PAA/PVA = 3:1.

\subsection{Effect of PAA/PVA ratio on the PAA/PVA crosslinking}

The SEM images of cross-linked PAA/PVA nanofiber mats are shown in Fig. 3. Thermal treatment of the nanofibers affected the fiber size and morphology. The average fiber sizes of the three mats were determined to be $580 \pm 129,621 \pm 170$ and $1164 \pm 267 \mathrm{~nm}$, for M1, M2 and M3, respectively. Each nanofiber mat showed a marked increase in nanofiber size after thermal crosslinking, which could be explained by two reasons: One is the melting and fusion of nanofibers due to exposure to high temperature treatment. Both PAA and PVA are glassy polymers and their transition temperatures (PVA at $85^{\circ} \mathrm{C}$ and PAA at $106^{\circ} \mathrm{C}$ ) (Arndt et al., 1999) were much lower than the crosslinking temperature $\left(145^{\circ} \mathrm{C}\right)$. As a result, $\mathrm{PAA}$ and PVA fibers were melted partially and fused mutually. The other reason is attributed to the 
esterification effect between the PAA and PVA polymers. PAA and PVA polymers were crosslinked via the esterification between $-\mathrm{COOH}$ (from PAA) and - $\mathrm{OH}$ (from PVA). With the formation of ester bonds, $\mathrm{H}_{2} \mathrm{O}$ molecules were generated as well. Thus, part of fibers was dissolved into the generated water and formed joints between adjacent nanofibers. The formed joints and the fusion between the nanofibers can also reinforce the physical strength and resistance to the mat deformation.

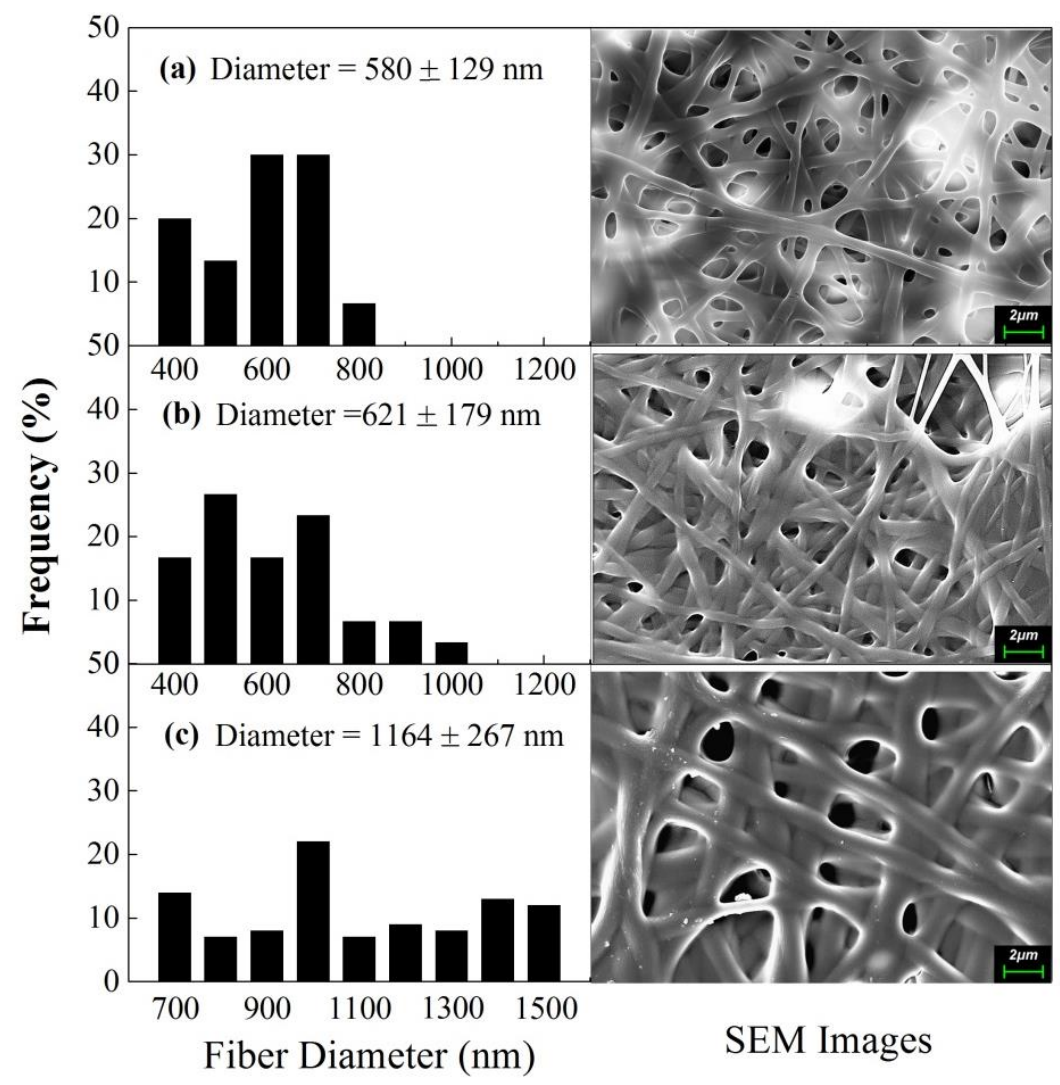

Figure 3. Effect of PAA/PVA ratio on the fiber sizes of cross-linked mats

(a) M1, PAA/PVA = 1:1; (b) M2, PAA/PVA = 2:1; (c) M3, PAA/PVA = 3:1.

Thermal cross-linking is usually carried out to render the PAA/PVA composite mat to be water-stable and mechanically strong. After thermal treatment, the as-spun mat turns from white into pale yellow color due to the carboxylic acid groups in PAA cross-linked with the hydroxyl groups in PVA (Li and Hsieh, 2005b). Following similar thermal treatment conditions reported in literature (Chun et al., 2005), the stability of the thermally-crosslinked mats in water 
having different PAA/PVA ratios was investigated based on their gelation content (Eq. 1). After treatment at $145^{\circ} \mathrm{C}$ for $30 \mathrm{~min}$ and then soaking in water for $24 \mathrm{~h}$, the gelation contents of M1, M2 and M3 were found to be $85 \%, 92 \%$ and $72 \%$, respectively (Fig. 4). This shows that some parts of the mat were still dissolved in water, suggesting that not all the molecules were successfully cross-linked. Interestingly, M2 showed the most stable mat in water among the samples. The difference in stability could be explained by looking at the mole fraction of each component polymer for cross-linking. The mass ratios of PAA and PVA were 1:1 (M1), 2:1 (M2) and 3:1 (M3), but their mole ratios are actually 0.61:1, 1.22:1 and 1.83:1. Hence, M2 obtained by the highest gelation content or water stability was probably because the mole ratio was closest to $1: 1$, generating the highest ester ratio and hence the lowest dissolution of individual PAA or PVA polymer. On the contrary, the mole ratio at 1.83:1 had the lowest gelation content because it had the most number of excess PAA molecules. Correspondingly, because of the dissolution of the mat and a thicker fiber size (Fig. 3c), the mass ratio at 3:1 had more voids in the mat and hence the highest porosity at $82.5 \%$ (Fig. 4.).

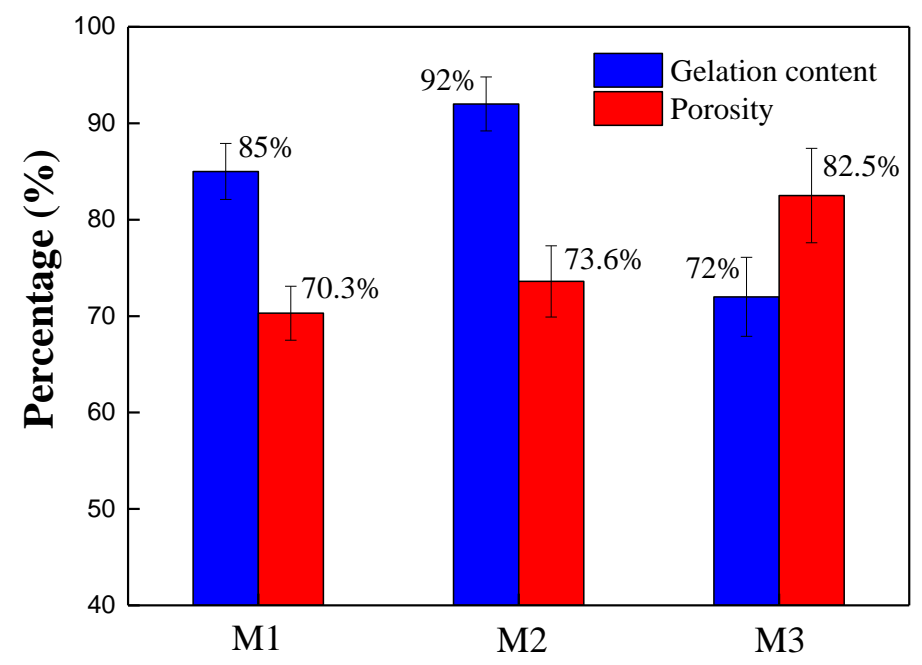

Figure 4. Effect of PAA/PVA ratio on the gelation content and porosity of cross-linked mats $(\mathrm{M} 1, \mathrm{PAA} / \mathrm{PVA}=1: 1 ; \mathrm{M} 2, \mathrm{PAA} / \mathrm{PVA}=2: 1 ; \mathrm{M} 3, \mathrm{PAA} / \mathrm{PVA}=3: 1)$ 
The FTIR curves for the cross-linked mats are illustrated in Fig. 5. It is obvious that each mat had a sharp peak at $1716 \mathrm{~cm}^{-1}$, which indicated the appearance of -COOH (Nesterova et al., 2000). The peak intensity of M3 was much higher than those of M2 and M1, but M2 was only slightly higher than M1. This could be explained by the ratio of ester. Although the PAA ratio of the as-spun M2 was twice than that of as-spun M1, however after thermal treatment, the ratio had changed. Identical numbers of $-\mathrm{COOH}$ and $-\mathrm{OH}$ were consumed during the generation of esters in each mat. For M1, the mass ratio of PAA/PVA was 1:1, wherein the mole ratio of the $-\mathrm{COOH}$ (from PAA)/ - OH (from PVA) was 0.61:1. In ideal condition, all the $-\mathrm{COOH}$ should have been reacted with $-\mathrm{OH}$ and no peak was to be expected at $1716 \mathrm{~cm}^{-1}$. However, because of the long-chain structures of both PAA and PVA polymers and the corresponding steric effects (Volkov et al., 1995), not all the-COOH groups were reacted with $-\mathrm{OH}$ groups, resulting in the existence of the weak peak at $1716 \mathrm{~cm}^{-1}$. This also ensures that there are still several - $\mathrm{COOH}$ groups available for capturing Fe(II) for the generation of nZVI in the next step. For M2, the mole ratio of the $-\mathrm{COOH} /-\mathrm{OH}$ was 1.22:1. Despite a higher PAA content of M2 than M1, during the crosslinking, most of the exceeding $-\mathrm{COOH}$ were reacted with the rest of $-\mathrm{OH}$ and formed more esters than $\mathrm{M} 1$. The lower peak intensity of $-\mathrm{OH}$ (3500$\left.3700 \mathrm{~cm}^{-1}\right)$ and higher peak intensity of R-COOR' $\left(1168 \mathrm{~cm}^{-1}\right)$ on M2 support this explanation. For $\mathrm{M} 3$, the mole ratio of the $-\mathrm{COOH} /-\mathrm{OH}$ was $1.83: 1$, indicating that $-\mathrm{COOH}$ groups were much more than $-\mathrm{OH}$ groups. Thus, there were still a large number of $-\mathrm{COOH}$ groups available after crosslinking. M3 had the highest intensities on each peak $(-\mathrm{OH},-\mathrm{CH} 2,-\mathrm{COOH}$ and $\mathrm{R}-$ COOR') due to the highest concentration of PAA and total polymers. 


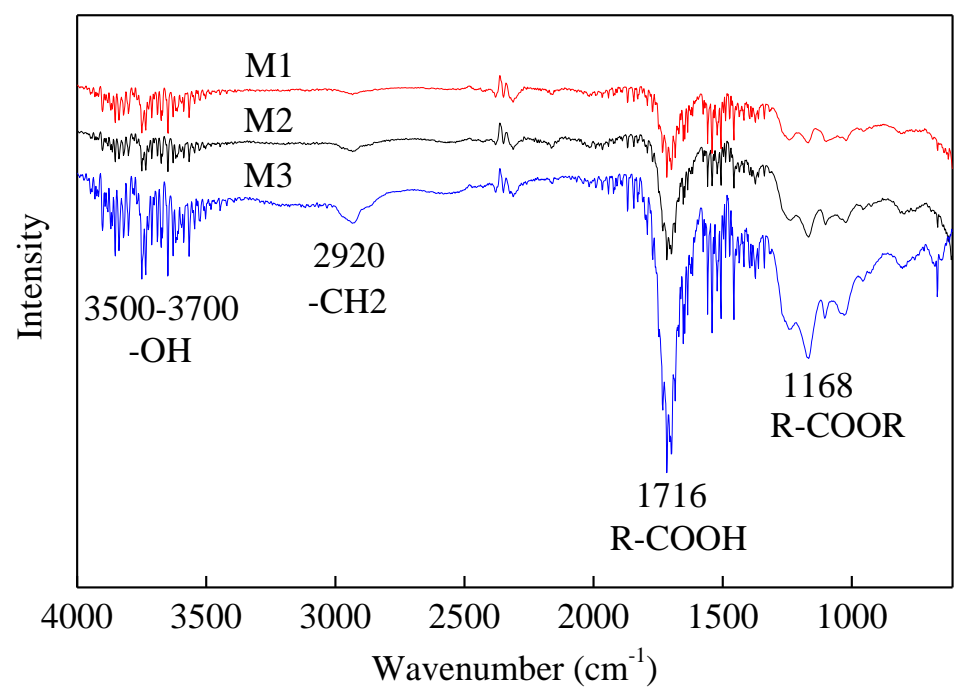

Figure 5. Effect of PAA/PVA ratio on the FTIR of cross-linked mats $(\mathrm{M} 1, \mathrm{PAA} / \mathrm{PVA}=1: 1 ; \mathrm{M} 2, \mathrm{PAA} / \mathrm{PVA}=2: 1 ; \mathrm{M} 3, \mathrm{PAA} / \mathrm{PVA}=3: 1)$

\subsection{Effect of PAA/PVA ratio on the immobilization of nZVI particles}

As shown in Fig. 6, the PAA/PVA ratio had a considerable influence on the immobilization of nZVI on the fibers. As expected, based from the SEM images, M3 had more nZVI particles immobilized on the fiber surface than M2 and M1. Basically, it is observable that there were two types of nZVI particles immobilized on the mats. One was on-surface nZVI particles, which were closely attached to the surface of fibers; the other was off-surface nZVI particles, which were off the surface of fibers and attached to other nZVI particles. For M1, the majority of nZVI particles were on-surface and only few nZVI particles were off-surface. In contrast, the majority of nZVI particles on M3 were off-surface and the on-surface nZVI particles were relatively less. The proportion of the two types of nZVI particles in M2 was just between that of M1 and M3. 


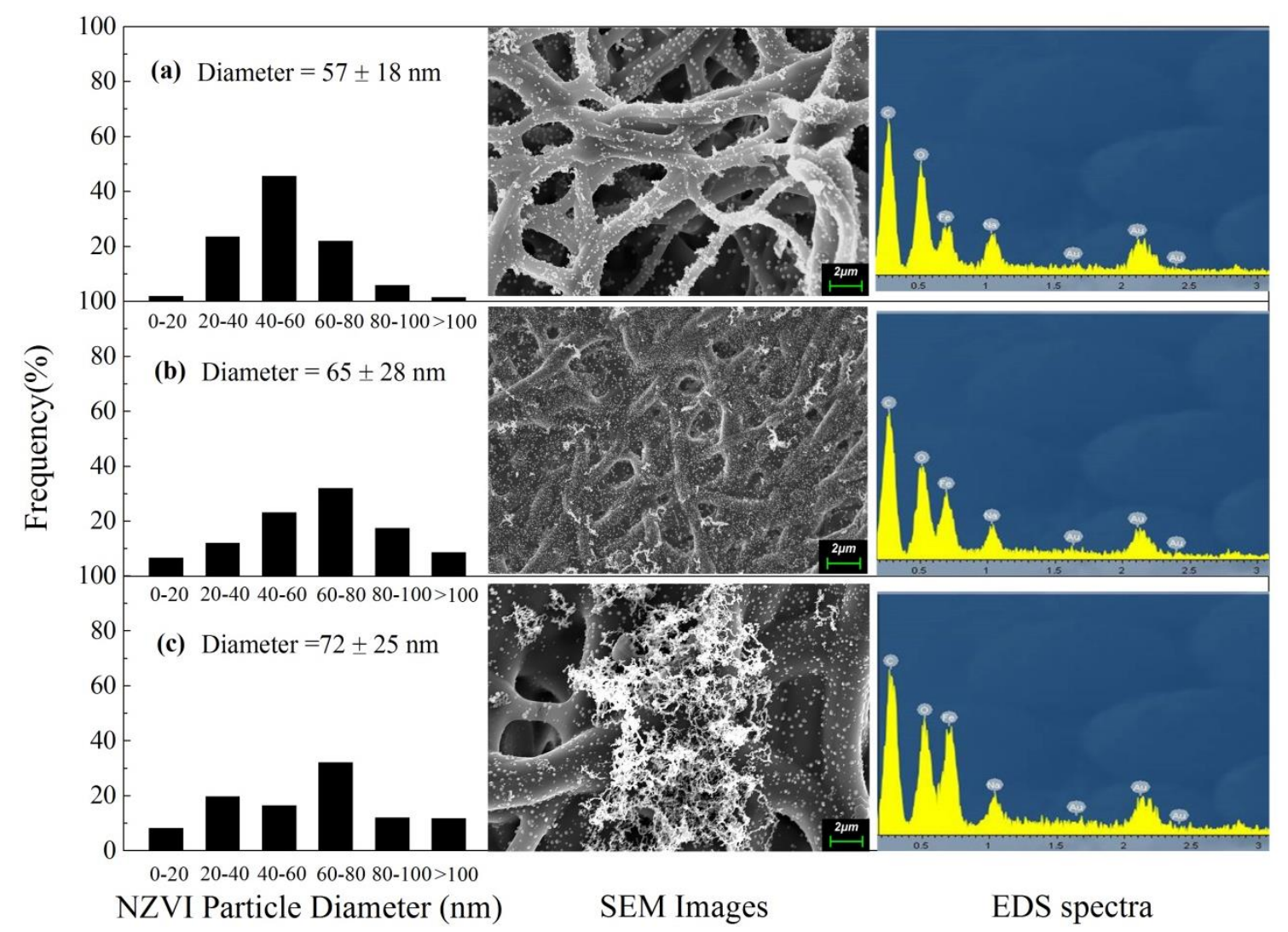

Figure 6. nZVI particle size distributions and SEM-EDS images of nZVI-immobilized mats (a) M1, PAA/PVA=1:1 (b) M2, PAA/PVA=2:1 (c) M3, PAA/PVA=3:1

Possible models were presumed to explain the formation mechanism and morphology of nZVIs on the fiber mats (Fig. 7). For M1 (Fig. 7a), most of $-\mathrm{COOH}$ groups on each PAA polymer were esterified with $-\mathrm{OH}$ groups of PVA and formed the backbone of nanofibers. The free $\mathrm{COOH}$ groups of PAA between - COO- groups could bond nZVI particles onto the branches of the backbone. Thus, nZVI particles were distributed on the surface of fibers with relatively uniform intervals. For M2 (Fig. 7b), part of $-\mathrm{COOH}$ groups on each PAA polymer were the same as M1 and the nZVI particles were bonded on the branches of the backbone. However, there were still some free $-\mathrm{COOH}$ groups of PAA out of the backbone available to bond nZVI particles. As a result of lack of the interval of $-\mathrm{COO}-$ groups, the $-\mathrm{COOH}$ groups were more compact and hence the nZVI particles were denser. For M3 (Fig. 6c), most of the free $-\mathrm{COOH}$ groups of PAA were out of the backbone and available to bond nZVI particles. Only few - 
$\mathrm{COOH}$ groups on each PAA polymer were esterified with $-\mathrm{OH}$ groups on the backbone of nanofibers. This resulted in more nZVI particles off the membrane surface. Meanwhile, the diameter of nZVI particles was found to increase with the increase in PAA/PVA ratio. The average nZVI particle sizes of the three mats were determined to be $57 \pm 18$ (M1), $65 \pm 28$ (M2) and $72 \pm 25 \mathrm{~nm}(\mathrm{M} 3)$, respectively. Since the nZVI particles on M1 were more dispersive, they had a lower size. On the contrary, the nZVI particles on M3 were more aggregated therefore leading to a larger size.

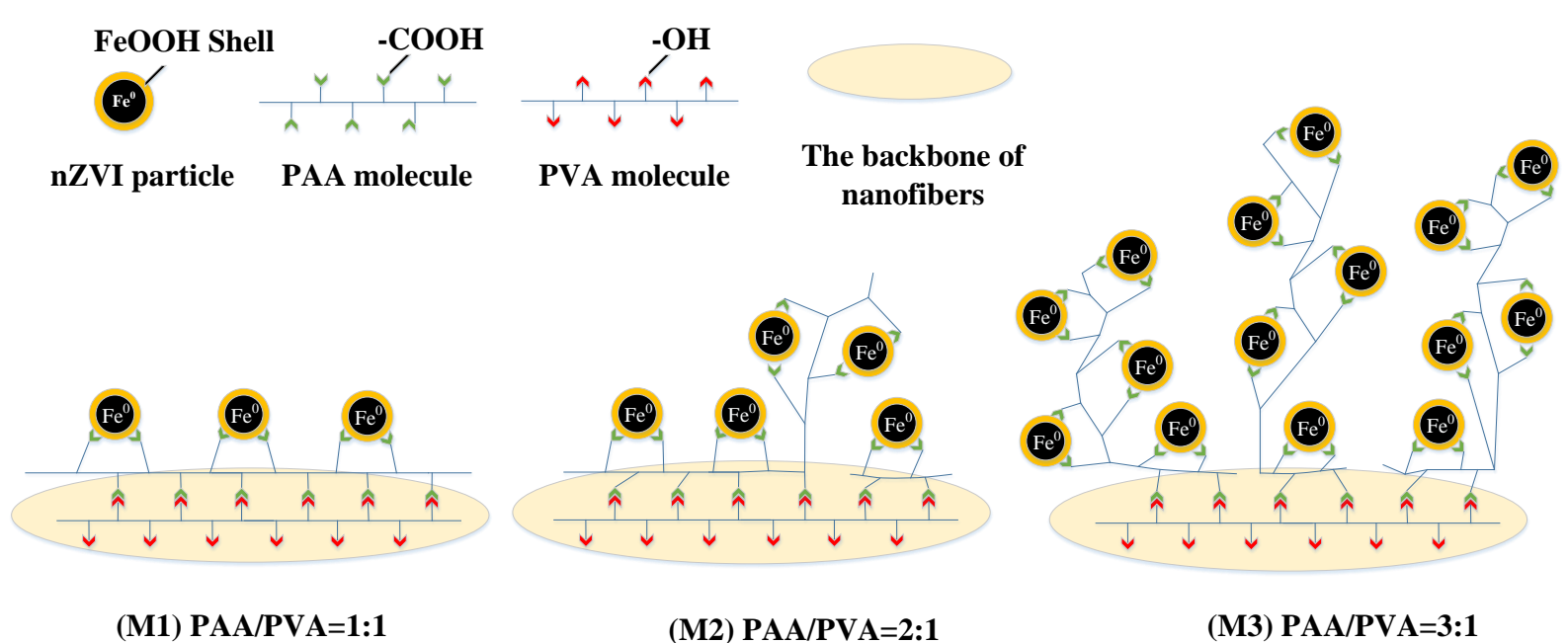

Figure 7. Models of the nZVI immobilization on mats.

Correspondingly, the result of EDS spectra was consistent with the SEM images. The peak intensity of Fe element of M3 (Fig. 6c) was much higher than those of M2 (Fig. 6b) and M1 (Fig.6a), which indicates that M3 immobilized the most nZVI particles. All the other elements in the three mats had similar peak intensities. There were no big differences between $\mathrm{C}$ and $\mathrm{O}$ elements, because the ratios of $\mathrm{C}$ and $\mathrm{O}$ in PAA and PVA monomer are similar. The $\mathrm{Na}$ element was from $\mathrm{NaBH} 4$ solution and $\mathrm{Au}$ element was from the coating material.

Fig. 8 shows the FTIR spectra of the nZVI-immobilized mats with different PAA/PVA ratios. It is obvious that the peak intensities of $-\mathrm{COOH}$ in each mat was dramatically decreased. 
Instead, a sharp peak at $1550 \mathrm{~cm}^{-1}$ for carboxylic ion $\left(-\mathrm{COO}^{-}\right)$became prominent. This is a direct evidence that most of $-\mathrm{COOH}$ had chelated with $\mathrm{Fe}$ ion and became $-\mathrm{COO}^{-}$. Thus, a higher PAA content had a higher peak intensity of $-\mathrm{COO}^{-}$. M3 had the highest peak intensity among the three mats, which means that M3 immobilized the most number of nZVI particles. Meanwhile, there was a sharp peak appearing at $1385 \mathrm{~cm}^{-1}$ for PAA-Fe (Cirtiu et al., 2011), which was another evidence that M3 immobilized more nZVI particles than M2 and M1. Three previous studies reported similar results (Ma et al., 2012; Nesterova et al., 2000; Xiao et al., 2009). Besides, adsorption from moisture may lead to the peak intensity of - OH (3000-3600 $\left.\mathrm{cm}^{-1}\right)$.

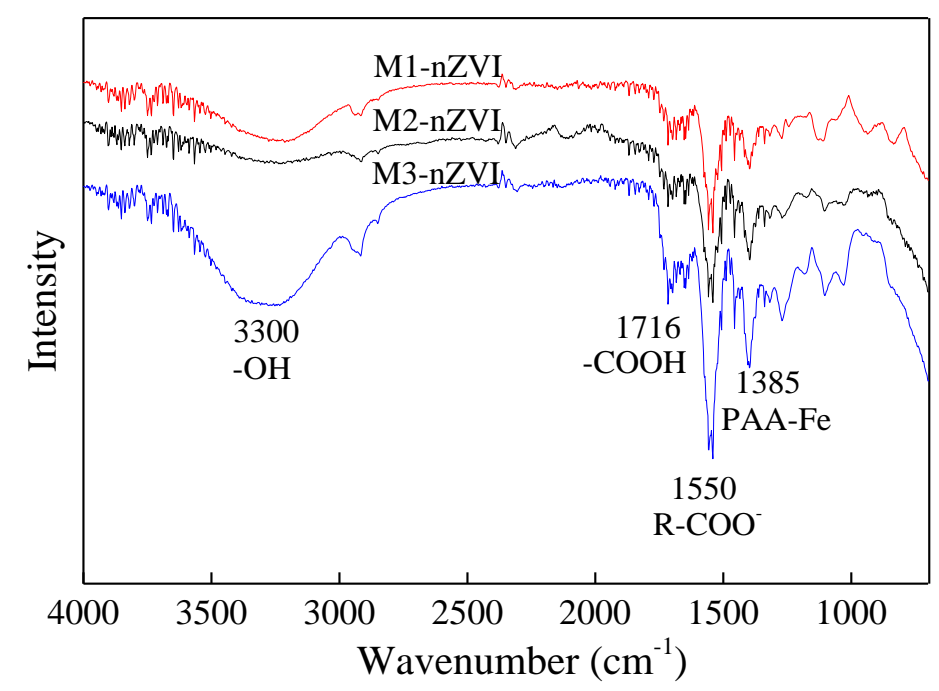

Figure 8. Effect of PAA/PVA mass (mole) ratio on the FTIR of nZVI-immobilized mats (M1-nZVI, PAA/PVA = 1:1; M2-nZVI, PAA/PVA = 2:1; M3-nZVI, PAA/PVA = 3:1).

TGA was used to characterize the loading capacity of immobilized nZVI particles on the cross-linked PAA/PVA nanofiber mats (Fig. 9). There was a slight weight loss on each mat upon heating up to $170{ }^{\circ} \mathrm{C}$, which should be due to the evaporation of ethanol and the loss of moisture in the mats (Ma et al., 2012). 


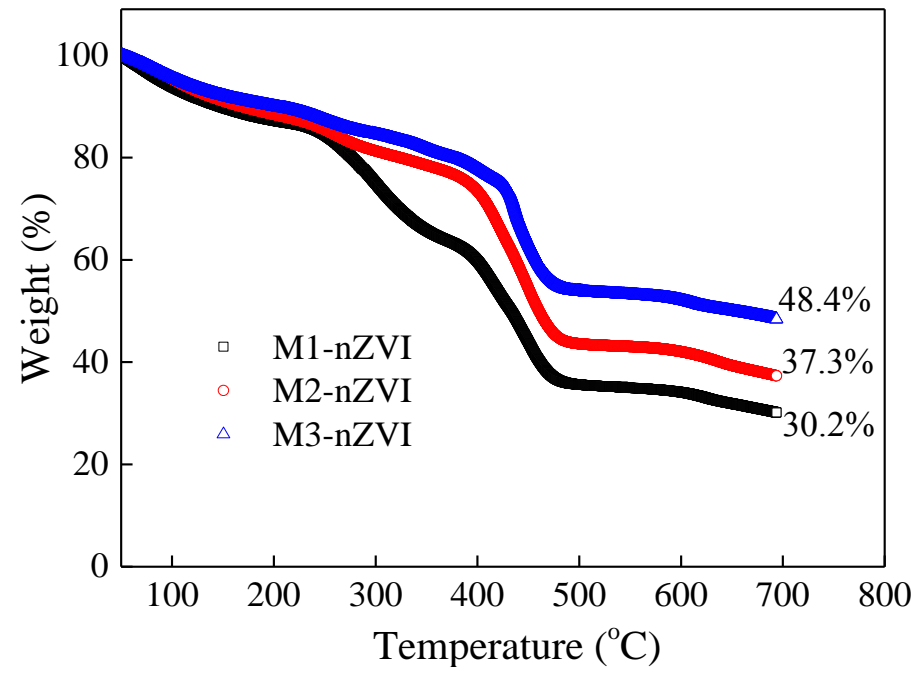

Figure 9. Effect of PAA/PVA mass (mole) ratio on the TGA of nZVI-immobilized mats $($ M1-nZVI, PAA/PVA = 1:1; M2-nZVI, PAA/PVA = 2:1; M3-nZVI, PAA/PVA = 3:1). 
Afterwards, the major weight loss of nZVI-immobilized mats at the region from 170 to $500 \circ \mathrm{C}$ is attributed to the decomposition of the PAA/PVA polymers. However, there were three stages during the decomposition (Arndt et al., 1999). On stage one, from 170 to $220{ }^{\circ}$, it was due to the dehydration of PAA with anhydrides formation (Maurer et al., 1987); on stage two, from 230 to $400^{\circ} \mathrm{C}$, it is attributed to the decomposition of anhydride, $-\mathrm{OH}$ and $-\mathrm{COOH}$ groups (Gilbert et al., 1962). The weight percentage of M1 reduced more significantly than that of M2 and M3, due to having a higher ratio of residual $-\mathrm{OH}$ groups; on stage three, from 400 to $500{ }^{\circ} \mathrm{C}$, there is a sharp weight decrease on each mat, which was probably due to the decomposition of esters. The percentage of M2 weight decreased most, which was consistent with its high ratio of esters since its mole ratio of $-\mathrm{COOH} /-\mathrm{OH}$ was closer to $1: 1$. When it comes to $700{ }^{\circ} \mathrm{C}$, all the polymeric nanofibers had been burned out, leaving nZVI particles as the residual mass. M3 remained the most nZVI particles at 48.4\% ( 2.5 times the figure for previous study (Ma et al., 2012)) while $\mathrm{M} 2$ and $\mathrm{M} 1$ obtained $37.3 \%$ and $30.2 \%$, respectively. This confirms that more nZVI particles were formed and attached to the fiber mats as also confirmed by other characterization methods explained above.

\subsection{Remediation performance of nZVI-decorated cross-linked fiber mats}

\subsubsection{Decolorization of methylene blue}

Methylene blue was selected to test the performance of nZVI-PAA/PVA nanofiber mats with various PAA/PVA ratios. To differentiate the effect of nZVI reduction from mat adsorption, the PAA/PVA mats and the nZVI-PAA/PVA mats were compared in this study. In

Fig. 10, it is obvious that all the mats with nZVI had higher removals than those of corresponding mats without nZVI. M3-nZVI had the highest removal of 94\% and M2-nZVI was at $86 \%$. Among the nZVI-PAA/PVA mats, M1-nZVI had the minimum removal at $78 \%$, 
which was even lower than that of M3 at $83 \%$. This could be explained by the significant adsorption effect of PAA/PVA mats. $-\mathrm{COOH}$ as well as $-\mathrm{OH}$ groups had a strong bonding with methylene blue. As a result, M3 with the highest number of $-\mathrm{COOH}$ showed a prominent removal. Meanwhile, M2 had the lowest removal at 49\%, even lower than the figure for M1 at $61 \%$. This was probably because the majority of $-\mathrm{COOH}$ and $-\mathrm{OH}$ groups on the $\mathrm{M} 2$ was used to form esters and hence the lowest the groups were left on the mat. Basically, although the difference in removal between mats with and without nZVI could not directly represent the reduction effect of nZVI, mainly because most of $-\mathrm{COOH}$ groups on the nZVI-immobilized mats had been occupied by nZVI particles and has decreased the effect of adsorption to methylene blue solution, it still has indicated that the combined process had a good performance on the decolorization of dye solution.

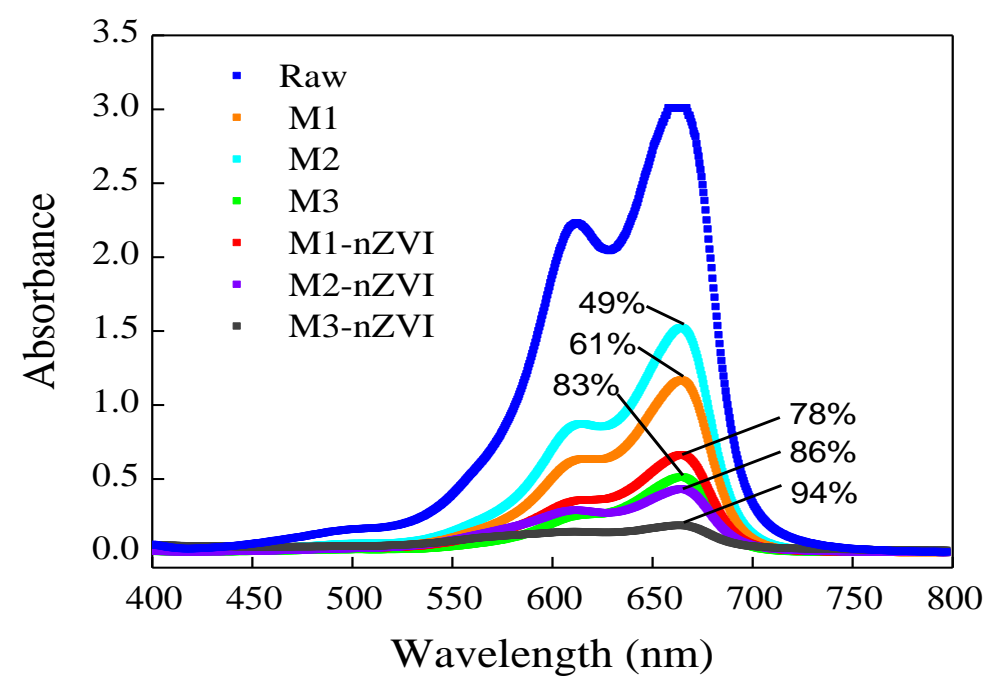

Figure 10. Methylene blue decolorization performance of cross-linked mats with (M1-nZVI, M2-nZVI and M3-nZVI) /without (M1, M2 and M3) nZVI particles. 


\subsubsection{Removal of $\mathrm{Cu}(\mathrm{II})$ ions}

To further check the capability of the present nZVI-decorated mats, $\mathrm{Cu}\left(\mathrm{NO}_{3}\right)_{2}$ was selected to test the performance of nZVI-PAA/PVA nanofiber mats with various PAA/PVA ratios as well. To differentiate the effect of nZVI reduction from mat adsorption, the PAA/PVA mats and the nZVI-PAA/PVA mats were compared in this study.

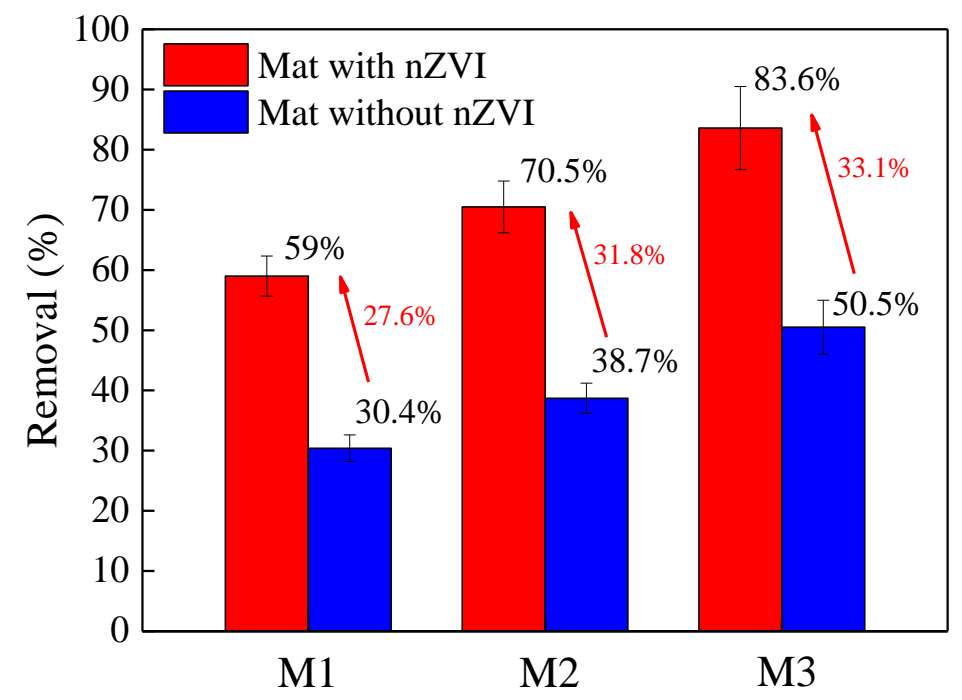

Figure 11. Effect of PAA/PVA ratio on the removal of $\mathrm{Cu}(\mathrm{II})$ ions

$(\mathrm{M} 1, \mathrm{PAA} / \mathrm{PVA}=1: 1 ; \mathrm{M} 2, \mathrm{PAA} / \mathrm{PVA}=2: 1 ; \mathrm{M} 3, \mathrm{PAA} / \mathrm{PVA}=3: 1)$

In Fig.11, all the mats with nZVI had higher removals than that of corresponding mats without nZVI. M3-nZVI had the highest removal at 83.6\%, while the removal of M2-nZVI and M1-nZVI were lower at $70.5 \%$ and $59 \%$. These neat mats had a decent effect on the removal on $\mathrm{Cu}(\mathrm{II})$ ions as well, particularly $\mathrm{M} 3$, whose removal was even higher than that of M1-nZVI and M2-NZVI, at 50.5\%. However, the adsorption effect on $\mathrm{Cu}$ (II) ion removal was obviously weaker than that of methylene blue, indicating that the adsorptive capability of $-\mathrm{COOH}$ and $\mathrm{OH}$ to $\mathrm{Cu}(\mathrm{II})$ ions was lower than to methylene blue. This could be explained by two reasons: One is that the adsorption mechanism of PAA/PVA mats to $\mathrm{Cu}(\mathrm{II})$ ion is complexation, which is mainly predominated by $-\mathrm{COOH}$ groups rather than $-\mathrm{OH}$ groups (Xiao et al., 2011). 
Therefore, the adsorption of -OH decreased significantly; the other is that bonding with $\mathrm{Cu}(\mathrm{II})$ ion required more $-\mathrm{COOH}$, after the $\mathrm{Cu}(\mathrm{II})$ ion is a bivalent heavy metal and methylthioninium(I) ion is a monovalent ion. Correspondingly, the adsorption of nZVI-loaded mats to $\mathrm{Cu}$ (II) ion were also lower than to methylene blue, thus having a lower removal on $\mathrm{Cu}$ (II) ion. Besides, M3 had the highest augment (33.1\%) from the neat mat to the nZVI-loaded mat also because it had the most $-\mathrm{COOH}$ groups.

Although the removal performance of nZVI-docorated mat to contaminants seemed not very remarkable, actually the weight of nZVI mat used in the raw water was very low. $8 \mathrm{mg}$ nZVI-immobilized mat was used to reduce $50 \mathrm{ml} 25 \mathrm{mg} / \mathrm{L}$ methylene blue and $\mathrm{Cu} 2+$ solution. With a very small weight ratio of nZVI mat to contaminated water, the removal could achieve at $94 \%$ and $83.6 \%$ respectively. This is equal to $147 \mathrm{mg} / \mathrm{g}$ (methylene blue/mat) and $131 \mathrm{mg} / \mathrm{g}$ $(\mathrm{Cu} / \mathrm{mat})$ removals. If we increase the weight of nZVI mat, the performance will be further improved. Xiao et al (Xiao et al., 2011) used the nZVI-immobilized MWCNT-PAA-PVA mat to remove $\mathrm{Cu} 2+$ and the copper uptake $(\mathrm{Cu} / \mathrm{mat})$ was $75.3 \mathrm{mg} / \mathrm{g}$, around half of our results. Horzum et al (Horzum et al., 2013) used the nZVI-immobilized mat to remove As (III) \& As (V), the arsenic uptake (As/mat) was $45 \mathrm{mg} / \mathrm{g}$ and $35 \mathrm{mg} / \mathrm{g}$ respectively, around only a quarter of our results. Basically, increasing the PAA/PVA ratio can effectively improve the performance of nZVI-immobilized mat.

\section{Conclusion}

In the present study, we indicates that increasing the PAA/PVA ratio had a great contribution to the immobilization of nZVI particles and hence improving the decolorization of methylene blue and the removal of $\mathrm{Cu}(\mathrm{II})$ ions from water. Similarly, it could have great potential in removing other organic contaminants and heavy metals. 
Essentially, the increase of PAA/PVA mass ratio is the increase of $-\mathrm{COOH} /-\mathrm{OH}$ mole ratio. The PAA/PVA mass ratios were 1:1 (M1), 2:1 (M2) and 3:1 (M3), but their -COOH/$\mathrm{OH}$ mole ratios are $0.61: 1,1.22: 1$ and $1.83: 1$. Theoretically, mat with a higher $-\mathrm{COOH} /-\mathrm{OH}$ mole ratio can immobilize more nZVI particles; meanwhile a further $-\mathrm{COOH} /-\mathrm{OH}$ mole ratio to $1: 1$ can achieve more porosity and adsorption to contaminants. In this study, M3 with the highest $-\mathrm{COOH} /-\mathrm{OH}$ mole ratio had the highest porosity $(82.5 \%)$ and the most $-\mathrm{COOH}$, which bonded with most nZVI particles (48.4\%). Therefore, M3-nZVI had the highest removals to methylene blue and $\mathrm{Cu}(\mathrm{II})$ ions at $94 \%$ and $83.6 \%$ respectively. Thus, mat with higher PAA/PVA ratio can immobilize more nZVI particles and had an excellent performance on the application of the groundwater remediation.

\section{Acknowledgement}

This research was funded by the Cooperative Research Centre for Contamination Assessment and Remediation of the Environment (CRC CARE).

\section{References}

Arndt, K., Richter, A., Ludwig, S., Zimmermann, J., Kressler, J., Kuckling, D., Adler, H., 1999. Poly (vinyl alcohol)/poly (acrylic acid) hydrogels: FT-IR spectroscopic characterization of crosslinking reaction and work at transition point. Acta Polymerica 50, 383-390.

Chun, H.J., Lee, S.B., Nam, S.Y., Ryu, S.H., Jung, S.Y., Shin, S.H., Cheong, S.I., Rhim, J.W., 2005. Preparation and swelling behavior of thermally cross-linked poly (vinyl alcohol) and poly (acrylic acid) hydrogel. Journal of Industrial and Engineering Chemistry 11, 556-560.

Cirtiu, C.M., Raychoudhury, T., Ghoshal, S., Moores, A., 2011. Systematic comparison of the size, surface characteristics and colloidal stability of zero valent iron nanoparticles pre-and post-grafted with common polymers. Colloids and Surfaces A: Physicochemical and Engineering Aspects 390, 95-104. 
Dror, I., Jacov, O.M., Cortis, A., Berkowitz, B., 2012. Catalytic transformation of persistent contaminants using a new composite material based on nanosized zero-valent iron. ACS applied materials \& interfaces 4, 3416-3423.

Gilbert, J., Kipling, J., McEnaney, B., Sherwood, J., 1962. Carbonization of polymers IThermogravimetric analysis. Polymer 3, 1-10.

Horzum, N., Demir, M.M., Nairat, M., Shahwan, T., 2013. Chitosan fiber-supported zerovalent iron nanoparticles as a novel sorbent for sequestration of inorganic arsenic. RSC Advances 3, 7828-7837.

Kocur, C.M., O'Carroll, D.M., Sleep, B.E., 2013. Impact of nZVI stability on mobility in porous media. J Contam Hydrol 145, 17-25.

Li, L., Hsieh, Y.L., 2005a. Ultra-fine polyelectrolyte fibers from electrospinning of poly(acrylic acid). Polymer 46, 5133-5139.

Li, L., Hsieh, Y.L., 2005b. Ultra-fine polyelectrolyte hydrogel fibres from poly (acrylic acid)/poly (vinyl alcohol). Nanotechnology 16, 2852-2860.

Lin, Y.H., Tseng, H.H., Wey, M.Y., Lin, M.D., 2010. Characteristics of two types of stabilized nano zero-valent iron and transport in porous media. Science of the Total Environment 408, 2260-2267.

Liu, C., Li, X., Ma, B., Qin, A., He, C., 2014. Removal of water contaminants by nanoscale zero-valent iron immobilized in PAN-based oxidized membrane. Applied Surface Science 321, 158-165.

Ma, B., Yu, W., Jefferson, W.A., Liu, H., Qu, J., 2015. Modification of ultrafiltration membrane with nanoscale zerovalent iron layers for humic acid fouling reduction. Water research 71, 140-149.

Ma, H., Huang, Y., Shen, M., Guo, R., Cao, X., Shi, X., 2012. Enhanced dechlorination of trichloroethylene using electrospun polymer nanofibrous mats immobilized with iron/palladium bimetallic nanoparticles. J Hazard Mater 211, 349-356.

Maurer, J., Eustace, D., Ratcliffe, C., 1987. Thermal characterization of poly (acrylic acid). Macromolecules 20, 196-202.

Nesterova, M.V., Walton, S.A., Webb, J., 2000. Nanoscale iron (III) oxyhydroxy aggregates formed in the presence of functional water-soluble polymers: models for iron (III) biomineralisation processes. Journal of inorganic biochemistry 79, 109-118.

O’Carroll, D., Sleep, B., Krol, M., Boparai, H., Kocur, C., 2013. Nanoscale zero valent iron and bimetallic particles for contaminated site remediation. Advances in Water Resources 51, 104-122. 
Schrick, B., Hydutsky, B.W., Blough, J.L., Mallouk, T.E., 2004. Delivery vehicles for zerovalent metal nanoparticles in soil and groundwater. Chemistry of Materials 16, 2187-2193. Tosco, T., Petrangeli Papini, M., Cruz Viggi, C., Sethi, R., 2014. Nanoscale zerovalent iron particles for groundwater remediation: a review. Journal of Cleaner Production 77, 10-21.

Volkov, A., Karachevtsev, I., Moskvina, M., Rebrov, A., Volynskii, A., Bakeev, N., 1995. The State of $\mathrm{Cu} 2+$ Ions and Highly Dispersed CuS immobilized in PVA-PAA polymer matrix. Journal of Inorganic and Organometallic Polymers 5, 295-305.

Wan, L.S., Ke, B.B., Wu, J., Xu, Z.K., 2007. Catalase immobilization on electrospun nanofibers: effects of porphyrin pendants and carbon nanotubes. The Journal of Physical Chemistry C 111, 14091-14097.

Wang, X., Chen, C., Liu, H., Ma, J., 2008. Preparation and characterization of PAA/PVDF membrane-immobilized $\mathrm{Pd} / \mathrm{Fe}$ nanoparticles for dechlorination of trichloroacetic acid. Water research 42, 4656-4664.

Wilkin, R.T., Acree, S.D., Ross, R.R., Puls, R.W., Lee, T.R., Woods, L.L., 2014. Fifteen-year assessment of a permeable reactive barrier for treatment of chromate and trichloroethylene in groundwater. Science of the total environment 468, 186-194.

Woo, Y.C., Kim, Y., Shim, W.G., Tijing, L.D., Yao, M., Nghiem, L.D., Choi, J.S., Kim, S.H., Shon, H.K., 2016. Graphene/PVDF flat-sheet membrane for the treatment of RO brine from coal seam gas produced water by air gap membrane distillation. Journal of Membrane Science $513,74-84$.

Woo, Y.C., Tijing, L.D., Park, M.J., Yao, M., Choi, J.S., Lee, S., Kim, S.H., An, K.J., Shon, H.K., 2015. Electrospun dual-layer nonwoven membrane for desalination by air gap membrane distillation. Desalination 403, 187-198.

Xiao, S., Ma, H., Shen, M., Wang, S., Huang, Q., Shi, X., 2011. Excellent copper(II) removal using zero-valent iron nanoparticle-immobilized hybrid electrospun polymer nanofibrous mats. Colloids and Surfaces A: Physicochemical and Engineering Aspects 381, 48-54.

Xiao, S., Shen, M., Guo, R., Huang, Q., Wang, S., Shi, X., 2010. Fabrication of multiwalled carbon nanotube-reinforced electrospun polymer nanofibers containing zero-valent iron nanoparticles for environmental applications. Journal of Materials Chemistry 20, 5700-5708. Xiao, S., Shen, M., Guo, R., Wang, S., Shi, X., 2009. Immobilization of zerovalent iron nanoparticles into electrospun polymer nanofibers: synthesis, characterization, and potential environmental applications. The Journal of Physical Chemistry C 113, 18062-18068. 
Yao, M., Woo, Y.C., Tijing, L.D., Shim, W.G., Choi, J.S., Kim, S.H., Shon, H.K., 2016. Effect of heat-press conditions on electrospun membranes for desalination by direct contact membrane distillation. Desalination 378, 80-91. 